\title{
SHORT STATURE IN CYPRIOT THALASSAEMIC CHILDREN
}

\author{
Major C. M. BATE; M.B., Ch.B., R.A.M.C. \\ British Military Hospital, Dhekelia \\ Dr. A. G. CUDWORTH, M.B., M.R.C.P. \\ University of Liverpool
}

SUMMARY: Studies were made on fasting growth hormone levels and iron load status. There were no significant differences in mean fasting plasma growth homone levels in 23 Cypriot children with homozygous $\beta$ - thalassaemia compared with 11 control Cypriot children of similar age. There was no association of fasting growth levels with transfused iron status or failure to achieve anticipated height. Stunted growth in thalassaemia is therefore unlikely to be due to a reduction in growth hormone availability and is probably secondary to gonadal dysgenesis.

\section{Introduction}

Children suffering from homozygous $\beta$-thalassaemia àre nearly always shorter than normal children of the same age, and they eventually attain a shorter final height (Signoretti, Della Porta and Pompeo 1965). Secondary sexual characteristics develop late or not at all, and whereas bone age is normal in early childhood, it is usually significantly retarded by the age of 8 to 9 years (Erlandson; Brilliant and Smith 1964). The cause of the shortness of stature is unknown. It has been suggested that an excessive deposition of iron in various organs including the pituitary, may give rise to a variety of endocrine defects (Zaino, Kuo and Roginsky 1969).

The aim of this report is to present data on fasting plasma growth hormone (GH) levels and iron load status in relation to height in 23 Cypriot children with homozygous $\beta$-thalassaemia compared with 11 normal Cypriot children of similar age.

\section{Patients and methods}

The thalassaemic group consisted of 19 Greek Cypriot and 4 Turkish Cypriot children (13 boys and 10 girls), ranging from 2 to 15 years in age (mean age: 6 years). All children were seen at regular intervals and maintained on a high blood transfusion regime aimed at keeping the minimum haemoglobin at approximately $10 \mathrm{~g} / 100 \mathrm{ml}$. The control group consisted of 8 Greek Cypriot and 3 Turkish Cypriot children ( 7 boys and 4 girls, ranging from 3 to 10 years of age (mean age: 7 years). All were sibs of children in the thalassaemic group, and all had been proven to be haematologically normal, by microscopic inspection of their peripheral blood films, estimation of their haemoglobin levels, and by determination of the percentage of haemoglobins $A_{2}$ and F present.

The details of the thalassaemic children are listed in Table I. Transfused iron load (mg of iron) was calculated from the total number of units of blood that each child had received. The measurement of height, sexual score and decimal age were performed according to Tanner, Whitehouse and Takaishi (1966), and the 'anticipated height' was calculated as the height each child would have attained had he or she maintained growth along the 50 th percentile. 
Table I

Chronological age, actual and anticipated height, and transfused iron load in 23 Cypriot children with homozygous $\beta$-thalassaenia

\begin{tabular}{|c|c|c|c|c|}
\hline Subject & $\begin{array}{c}\text { Decimal chronological } \\
\text { age (years) }\end{array}$ & $\begin{array}{l}A_{\mathrm{k}} \text { ctual height } \\
(\mathrm{cm})\end{array}$ & Anticipated height & $\begin{array}{l}\text { Iron load } \\
\text { (mg) }\end{array}$ \\
\hline $\begin{array}{r}1 \\
2 \\
3 \\
* 4 \\
5 \\
6 \\
* 7 \\
8 \\
9 \\
* 10 \\
11 \\
* 12 \\
13 \\
* 14 \\
* 15 \\
* 16 \\
17 \\
* 18 \\
* 19 \\
* 20 \\
21 \\
* 22 \\
* 23\end{array}$ & $\begin{array}{r}2.34 \\
2.65 \\
2.99 \\
3.02 \\
3.24 \\
3.25 \\
3.38 \\
3.60 \\
4.01 \\
4.54 \\
6.35 \\
6.46 \\
7.06 \\
7.85 \\
8.47 \\
9.96 \\
10.42 \\
10.56 \\
11.11 \\
11.67 \\
13.16 \\
15.46 \\
17.67 \\
\end{array}$ & $\begin{array}{r}89.0 \\
94.0 \\
96.0 \\
98.0 \\
96.7 \\
94.0 \\
94.0 \\
94.0 \\
101.0 \\
98.0 \\
118.0 \\
99.0 \\
116.0 \\
114.5 \\
127.0 \\
129.0 \\
125.5 \\
141.0 \\
136.3 \\
141.4 \\
151.0 \\
152.0 \\
130.0\end{array}$ & $\begin{array}{r}90.5 \\
91.0 \\
92.5 \\
93.8 \\
93.8 \\
94.0 \\
96.8 \\
97.0 \\
96.7 \\
100.5 \\
105.0 \\
116.8 \\
115.8 \\
120.3 \\
123.9 \\
128.0 \\
135.0 \\
138.4 \\
139.0 \\
141.8 \\
144.1 \\
151.9 \\
166.5 \\
161.1\end{array}$ & $\begin{array}{r}4,100 \\
4,385 \\
3,465 \\
4,750 \\
7,000 \\
2,994 \\
5,750 \\
3,951 \\
7,360 \\
5,750 \\
11,700 \\
11,750 \\
5,250 \\
5,500 \\
11,500 \\
10,750 \\
32,500 \\
8,500 \\
5,750 \\
5,500 \\
10,750 \\
7,000 \\
13,000\end{array}$ \\
\hline
\end{tabular}

* Denotes splenectomy

Following an overnight fast, blood samples for GH estimation were collected several minutes after the insertion of an intravenous cannula for the purpose of maintenance blood transfusion. Plasma was separated immediately and stored at minus $20^{\circ} \mathrm{C}$ until the time of assay. All the samples from the thalassaemic and control children were assayed in duplicate within one assay employing a double antibody method based on that described by Hales and Randle (1963), using Wellcome antiser and a first international reference preparation (IRP) for growth hormone (obtained from MRC, Ref. 66/217).

\section{Results}

The children with the greatest reduction in anticipated height tended to have the higher transfused iron load values (Table I), and most of these children had at some stage undergone splenectomy. Seven children (subjects 10,12,14,16, 17, 22 and 23 in Táble I) were markedly stunted and three of these (subjects 14,17 and 23) had unequivocal radiological evidence of retarded bone age. Subject 22 (a male aged 15.5 years), and subject 23 (a female aged 17.7 years), had only achieved Stage III and Stage II of puberty respectively.

The individual plasma GH levels are listed in Table II. Using the student $t$ test for unpaired data there is no significant difference between the mean plasma GH values, and an analysis of variance also confirms that there is no significant variation in the fasting GH levels between the two groups. In addition, there is no association between these GH levels and either the iron load status or the apparent failure to achieve anticipated height. 
Table II

Individual fasting GH levels (and Mean \pm S.D.) for 23 children with homozygous $\beta$ - thalassaemia and 11 controls of similar age

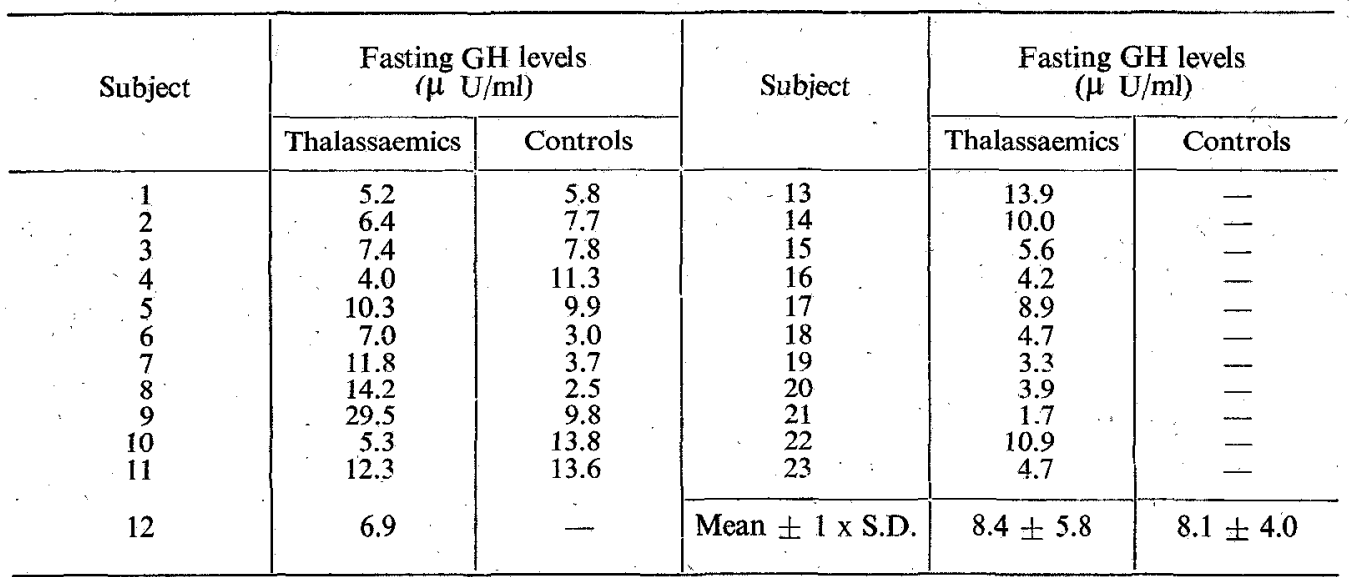

\section{Discussion}

The pituitary gland contains approximately $10 \mathrm{mg}$ of growth hormone, and acute stimulation of GH secretion can only lead to the release of a very small fraction of the total amount of hormone stored in the gland (Sonksen 1974). Although the thalassaemic children were accustomed to having repeated blood transfusions, the insertion of an intravenous cannula was nevertheless a relatively traumatic experience and thus provided both a physical and psychological stress capable of stimulating $\mathrm{GH}$ secretion. There is no significant difference in the mean plasma GH values compared with the normal children who had an ordinary venepuncture which was likely to have been equally stressful. Although there is a wide inter-individual variation in basal growth hormone levels, there is no significant difference between the two groups. This is suggestive evidence that children suffering from homozygous $\beta$ - thalassaemia do not have a reduction in circulating GH levels, but no conclusion can be drawn concerning the biological activity of the circulating $\mathrm{GH}$ in these children.

It has been postulated that either growth hormone per se is altered to sulphation factor or it reacts with a substrate to produce sulphation factor which in turn acts on the end organ (McGarry and Beck 1972). Elevated levels of sulphation factor have been observed in patients with gonadal dysgenesis which fails to improve with human GH therapy and it has been suggested that this might represent end organ failure (Daughaday, Laron and Heins 1969). There is a complex interaction of the secondary sex hormones with GH release, and delayed puberty may stimulate partial GH deficiency (Sonksen 1974). In contrast to the pituitary which has the ability to store large amounts of $\mathrm{GH}$, other endocrine organs, notably the adrenal cortex, synthesise and release hormones on demand. Retardation in the development of secondary sexual characteristics and markedly stunted growth were particularly evident in the two oldest children in the study. It is speculated that iron deposition in the adrenal glands, ovaries and testes is therefore likely to result in a failure of synthesis of the secondary sex hormones which may lead to delayed puberty and stunted growth. This supported by the finding of low 
urinary keto-steroids in five out of seven cases with homozygous thalassaemia (Zaino, Kuo and Roginsky 1969), and the failure of secondary sexual development with stunted growth in juvenile haemochromatosis (Perkins et al 1965).

It is concluded that the cause of short stature in thalassaemia is more probably related to gonadal dysfunction and/or a possible failure of sulphation factor end organ effect, rather than any primary deficiency in spontaneous growth hormone secretion.

\section{Acknowledgements}

We thank Professor D. J. Weatherall for his support and Mrs. S. Clough for technical assistance. The work was supported in part by the Medical Research Committee of the Mersey Regional Health Authority.

\section{REFERENCES}

Daughaday, W. H., Laron, Z. and Heins, J. N. (1969). Clin. Res. 17, 472.

Erlandson, M. E., Britliant, R, and Smith, C. H. (1964). Ann. N. Y. Acad. Sci. 119, 727.

Hales, C. N. and RANDle, P. J. (1963). Biochem. J. 88, 137.

McGARrY, E. E: and BECK, J. C. (1972). Metabolic effects of human hormone In Human Growth Hormone. William Heinemann Medical Books Ltd. London.

Perkins, K. W., McKinnes, I. W. S., Blackburn, C. R. B. and Beal, R. W. (1965). Amer. J. Med. 39, 118.

Sigmoretti, A., Della Porta, G. and Pompeo, I. (1965). Minervá pediat. 17, 1284. 